\title{
Synthesis and Properties of Thermotropic Copoly(ester imide)s
}

\author{
Dewen Dong, ${ }^{\dagger}$ Rui Zhang, Guang Li, and Yushan Ni \\ Polymer Physics Laboratory, Changchun Institute of Applied Chemistry, Chinese Academy of Sciences, \\ Changchun 130022, People's Republic of China
}

(Received May 19, 1998)

\begin{abstract}
A dicarboxylic acid, $N, N^{\prime}$-hexane-1,6-diylbis(trimellitimide), was prepared by the reaction of trimellitic anhydride with 1,6-hexane diamine. From the diacid, a series of copoly(ester imide)s had been synthesized by thermal condensation with $p$-hydroxybenzoic acid and diphenols with different structures. Properties of the resulting copoly(ester imide)s were characterized by polarized light microscopy, differential scanning calorimetry (DSC) and wide-angle X-ray diffraction (WAXD). Most of the copoly(ester imide)s formed a nematic phase over a wide temperature range above their melt. The effects of the copoly(ester imide)s composition and the structures of diphenols on the temperature related to liquid crystalline transition were investigated.

KEY WORDS Copoly(ester imide) / Thermotropic Liquid Crystal / Nematic Phase / Thermal

Condensation / $N, N^{\prime}$-Hexane-1,6-diylbis(trimellitimide) / $p$-Hydroxybenzoic Acid /
\end{abstract}

Liquid crystalline polymers have been a relatively new range of high temperature engineering thermoplastics, because the anisotropy of liquid crystalline mesophase can offer the possibility of production of novel highperformance materials, exhibiting excellent properties, due to a proper arrangement of macromolecules in the mesophase during the processing. ${ }^{1-5}$ In the past decade, extensive studies of liquid crystalline poly(ester imide)s have been made, not only for scientific importance but also for serious practical goals. The idea of the research is to combine the interesting properties of mesophase with the specific behaviors of polyimides as engineering plastics. Yet to the best of our knowledge the most of these poly(ester imide)s are homopoly(ester imide)s based on a regular sequence of rigid rodlike aromatic imide "mesogenic" units and flexible "spacers" units. ${ }^{6-9}$ With regard to application as thermotropic engineering plastics the mesogenic temperature range of these homopoly(ester imide)s is so small (about $20^{\circ} \mathrm{C}$ ) that the processing from the anisotropic melt is difficult or impossible. Therefore, the present work have the purpose of synthesizing copoly(ester imide)s with a broad mesogenic temperature range by introducing p-oxybenzoyl (POB) unit into the polymer backbone. The POB unit is chosen for its ability to generate a given kind of mesogen in the repeat units of main-chain thermotropic liquid crystalline polyesters. Furthermore, the effects of copolymer composition and structures of diphenols on the transition temperature and mesophase type formed above the melt are investigated.

\section{EXPERIMENTAL}

\section{Materials}

Trimellitic anhydride was purchased from FLUKA and recrystallized from a mixture of acetic anhydride and toluene (mp: $\left.164-165^{\circ} \mathrm{C}\right)$. 1,6-Hexanediamine, $p$-hydroxybenzoic acid (PHB) and all diphenols were of reagent grade and used without further purification.

$N, N^{\prime}$-Hexane-1,6-diylbis(trimellitimide) was prepared by trimellitic anhydride and 1,6-hexanediamine according to published methods. ${ }^{6,10}$ Bis(4-hydroxyphenyl)ketone was prepared from $p$-hydroxybenzoic acid and phenol according to a patent method. ${ }^{11}$

\section{Polycondensation}

The polycondensation process is briefly illustrated in Scheme 1. For a typical procedure: $50 \mathrm{mmol}$ of $p$ hydroxybenzoic acid (PHB), $25 \mathrm{mmol}$ dicarboxylic acid, $25 \mathrm{mmol}$ diphenol, $30 \mathrm{ml}$ of acetic anhydride, and $20 \mathrm{mg}$ zinc acetate were added into a $250 \mathrm{ml}$ three-neckedflask equipped with a mechanical stirrer, a Dean-Stark trap with condenser, gas inlet and outlet tubes. The reaction mixture was refluxed under a slow stream of nitrogen with stirring for $2 \mathrm{~h}$, then the reaction system was heated to and kept at $300^{\circ} \mathrm{C}$ for $4 \mathrm{~h}$. During the process, acetic acid and excess acetic anhydride were removed. Finally, introduction of nitrogen was halted and a vacuum was applied for $1 \mathrm{~h}$. After cooling the resulting polymer was isolated mechanically.

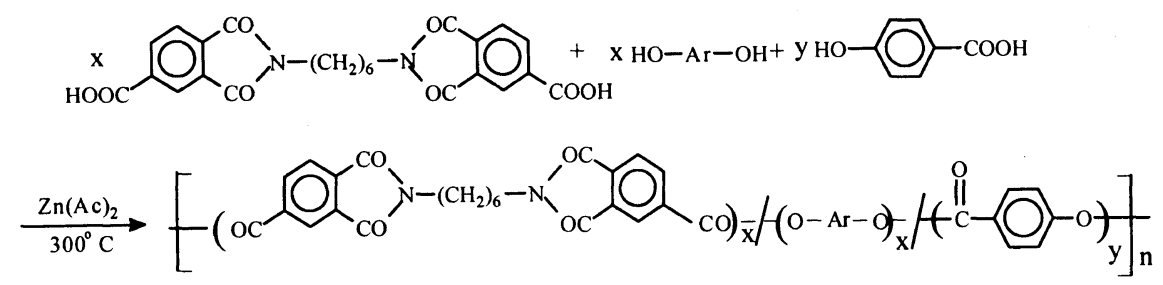

Scheme 1.

\footnotetext{
$\dagger$ To whom all correspondence should be addressed.
} 
Table I. Yields and properties of copoly(ester imide)s 1a-1n

\begin{tabular}{|c|c|c|c|c|c|c|c|c|c|c|}
\hline \multirow{2}{*}{ Polym. } & \multirow{2}{*}{$\mathrm{Ar}$} & \multirow{2}{*}{$\frac{\mathrm{PHB}}{\mathrm{mol} \%}$} & \multirow{2}{*}{$\frac{\text { Yields }}{\%}$} & \multirow{2}{*}{$\frac{\eta^{\mathrm{a}}}{\mathrm{dl} \mathrm{g} \mathrm{g}^{-1}}$} & \multirow{2}{*}{$\frac{T_{\mathrm{g}}^{\mathrm{b}}}{{ }^{\circ} \mathrm{C}}$} & \multirow{2}{*}{$\begin{array}{l}T_{\mathrm{m}} \\
{ }^{\circ} \mathrm{C}\end{array}$} & \multirow{2}{*}{$\begin{array}{r}T_{\mathrm{i}} \\
{ }^{\circ} \mathrm{C}\end{array}$} & \multirow{2}{*}{ Birefringence $^{c}$} & \multicolumn{2}{|c|}{ Temp with weight $\operatorname{loss}^{\mathrm{d}} /{ }^{\circ} \mathrm{C}$} \\
\hline & & & & & & & & & $2 \%$ & $5 \%$ \\
\hline $1 \mathrm{a}$ & & 20 & 89 & 0.21 & 100 & 228 & 247 & Weak & 347 & 355 \\
\hline 1b & & 30 & 91 & 0.23 & 92 & 227 & 249 & Weak & 348 & 362 \\
\hline 1c & & 40 & 93 & 0.32 & 95 & 228 & - & Strong & 354 & 380 \\
\hline 1d & & 50 & 95 & 0.60 & 89 & 215 & - & Strong & 360 & 392 \\
\hline 1e & & 60 & 92 & 0.45 & 88 & 207 & - & Strong & 358 & 410 \\
\hline 1f & & 70 & 96 & 0.24 & 75 & 198 & - & Strong & 370 & 415 \\
\hline $1 \mathrm{~g}$ & & 80 & 92 & Insol & 83 & 287 & - & Strong & 382 & 433 \\
\hline 1h & & 50 & 98 & 0.61 & 95 & 259 & - & Strong & 369 & 420 \\
\hline 1i & & 50 & 93 & 0.29 & 104 & 267 & - & Strong & 360 & 404 \\
\hline $\mathbf{1 j}$ & & 50 & 92 & 0.26 & 97 & 240 & - & Strong & 365 & 426 \\
\hline $1 k$ & & 50 & 86 & 0.29 & 115 & - & - & None & 355 & 383 \\
\hline $1 \mathrm{~m}$ & & 50 & 88 & 0.37 & 142 & - & - & None & 330 & 357 \\
\hline 1n & & 50 & 89 & 0.24 & 102 & - & - & None & 345 & 378 \\
\hline
\end{tabular}

${ }^{\mathrm{a}}$ Inherent viscosity measured in dichloromethane-trifluoroacetic acid $\left(10: 1\right.$ by volume), with $c=0.1 \mathrm{~g} \mathrm{dl}{ }^{-1}$ at $25^{\circ} \mathrm{C}$. ${ }^{\mathrm{b}} T_{\mathrm{g}}, T_{\mathrm{m}}, T_{\mathrm{i}}$ from $\mathrm{DSC}$ measurements with a heating rate of $20^{\circ} \mathrm{Cmin}^{-1}$. ${ }^{\mathrm{c}}$ Birefringence phenomenon observed by polarizing microscopy. ${ }^{\mathrm{d}}$ From $\mathrm{TGA}$ measurements with a heating rate of $10^{\circ} \mathrm{C} \mathrm{min}^{-1}$ in air.

\section{Measurements}

Differential scanning calorimetry (DSC) measurements were conducted at a heating rate of $20^{\circ} \mathrm{C} \mathrm{min}^{-1}$ with a Perkin-Elmer DSC-7 in alumimum pans. Thermogravimetric analyses (TGA) were obtained on a Perkin-Elmer TGS-7 at a heating rate of $10^{\circ} \mathrm{C} \mathrm{min}^{-1}$ in air.

Wide-angle X-ray diffraction (WAXD) curves were measured with a powder diffractometer PW-1700 by means of $\mathrm{Cu}-K_{\alpha}$ radiation and $\mathrm{Ni}$ filter.

\section{RESULTS AND DISCUSSION}

\section{Synthesis of Monomers and Copoly(ester imide)s}

$N, N^{\prime}$-Hexane-1,6-diylbis(trimellitimide) and bis(4-hydroxyphenyl)ketone served as monomers of all copoly(ester imide)s were synthesized according to the literature, respectively. Their structures were identified by ${ }^{1} \mathrm{H}$ NMR, IR spectra, and elemental analyses which were in good agreement with those in the literaure. In the present work, all copoly(ester imide)s were synthesized by thermal condensation in the presence of zinc acetate as transesterification catalyst. In fact the polycondensation was a transesterification procedure involving $\mathrm{PHB}$, various bisphenols and dicarboxylic acid containing two built-in imide rings. Acetic anhydride used here in excess acted as not only the solvent for ease of dissolution of some monomer and the oligomer but also acetylation reagent of $\mathrm{PHB}$ and bis(4-hydroxyphenyl)ketone. Thus, the direct melt polycondensation under discussion combined the acetylation of monomer and esterification to a one-pot reaction.

\section{Properties of Copoly(ester imide)s Containing Different Molar Ratio of $\mathrm{PHB}$}

In order to minimize the effect of the previous thermal history, as-synthesized polymer was heated in the DSC apparatus to $330^{\circ} \mathrm{C}$ at a rate of $20^{\circ} \mathrm{Cmin}^{-1}$ under nitrogen, followed by cooling to room temperature at a rate of $10^{\circ} \mathrm{C} \mathrm{min}^{-1}$. The specimen was then subjected to a second heating/cooling cycle and the data were plotted. The results are listed in Table I. The heating traces of all copoly(ester imide)s displayed a glass transition and one or two endotherms (Figure 1). It was 
found that the glass transition temperatures $\left(T_{\mathrm{g}} \mathrm{s}\right)$ as well as melting temperatures $\left(T_{\mathrm{m}} \mathrm{s}\right)$ of these copoly(ester imide)s slowly diminished with increasing of PHB molar ratio and showed minimum at $70 \mathrm{~mol} \%$. Afterwards, it increased.

In the case of $\mathbf{1 a}$ and $\mathbf{1 b}$, two closely neighboring endotherms $\left(T_{\mathrm{m}}, T_{\mathrm{i}}\right)$ were observable in the heating trace and one broad exotherm was detectable in the

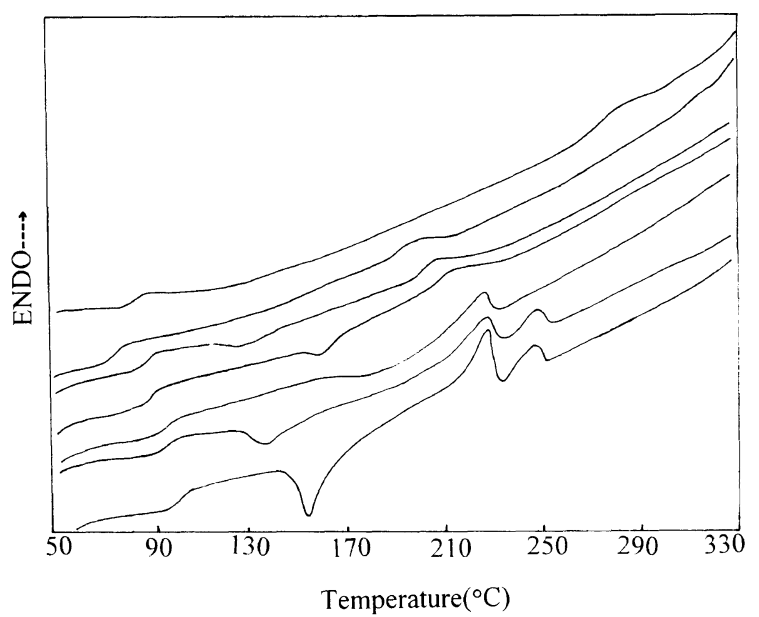

Figure 1. DSC curves of poly(ester imide)s 1a-1g (heating rate: $20^{\circ} \mathrm{C} \mathrm{min}^{-1}$ ).

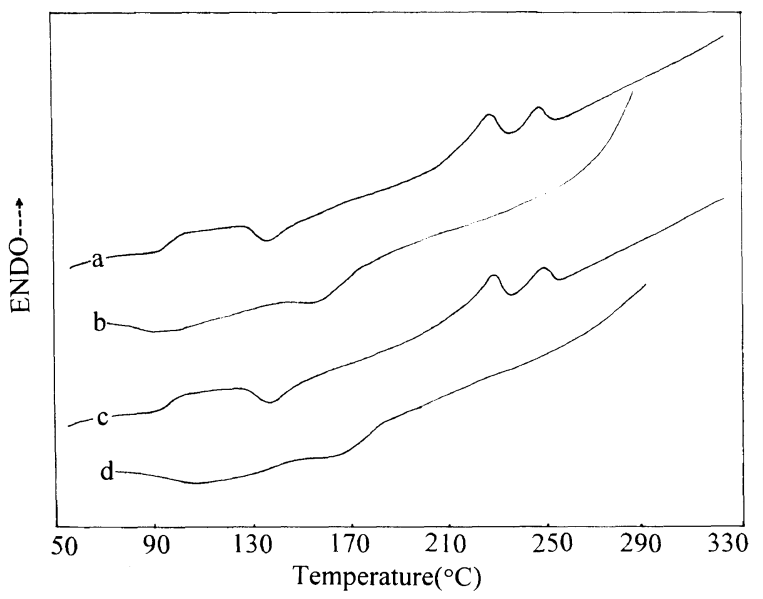

Figure 2. DSC curves of poly(ester imide) 1b (heating rate/cooling rate: $20^{\circ} \mathrm{C} \mathrm{min}^{-1}$ ). a, first heating; $b$, first cooling; c, second heating; $\mathrm{d}$, second cooling.

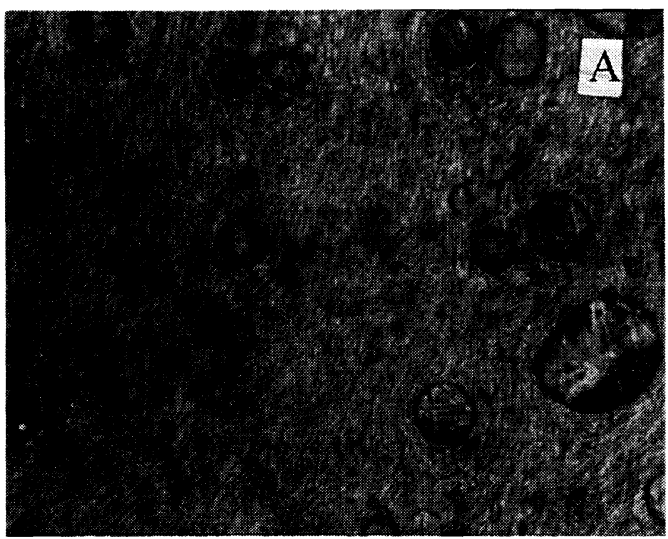

cooling trace (Figure 2). The fact that the DSC traces in the first and second heating/cooling cycle were identical indicated that the two endotheroms did not result from crystallites of different size or the previous thermal history. Kricheldorf and co-workers found the similar phenomenon in studying copoly(ester imide)s containing POB unit. ${ }^{12}$ However, they could not give a clearup interpretation. In our study, as demonstrated by observation under polarized light microscopy, the two endotherms were defined as the temperature range of a mesophase. Birefringence could be observed by high shear from their melt. An isotropic melt was formed immediately above their second endotherm. Whereas in the case of $1 \mathbf{c}-\mathbf{1 g}$, only one small endotherm $\left(T_{\mathrm{m}}\right)$ could be detected which represented the transition from solid state to anisotropic melt. The mesophase nature of the melt was indicated by "thread schlieren texture" (Figure 3A) that fitted well with a published texture of a typical nematic phase for random copolyesters of PHB. ${ }^{13-16}$ Figure 3 shows an optical texture observed for 1d. After shearing the polymer melt between a glass slide and cover slip, a typical "banded texture" (Figure 3B) was observed. In addition, it was found that the banded texture was formed during relaxation of shear orientation instead of during shear. Many researchers had also found the texture in nematic or cholesteric mesophase of thermotropic liquid crystalline mainchain polymers. ${ }^{17,18}$ The mesophase temperature range of all copoly(ester imide)s were also revealed by observation from polarized light microscopy. However, the isotropization could not be observed in most cases. In the cases of copoly(ester imide)s with less than $40 \mathrm{~mol} \%$ of PHB, isotropic temperature $\left(T_{\mathrm{i}}\right)$ was very low. Their mesophase only existed over a relatively narrow temperature range of $20-25^{\circ} \mathrm{C}$. The $T_{\mathrm{i}} \mathrm{s}$ of copoly(ester imide)s containing $40-80 \mathrm{~mol} \%$ of $\mathrm{PHB}$ (1c-1g) were too high to appear because of the beginning of thermal decomposition at $350^{\circ} \mathrm{C}$. However, the birefringence and texture could be observed from their melting point up to $400^{\circ} \mathrm{C}$. The mesophase temperature of these copoly(ester imide)s covered a broader range which made it possible to be processed from their mesogenic melt.

Copoly(ester imide) (1g) containing higher level PHB $(80 \mathrm{~mol} \%)$ revealed insolubility in dichloromethanetrifluoroacetic acid (10:1 by volume). However, its

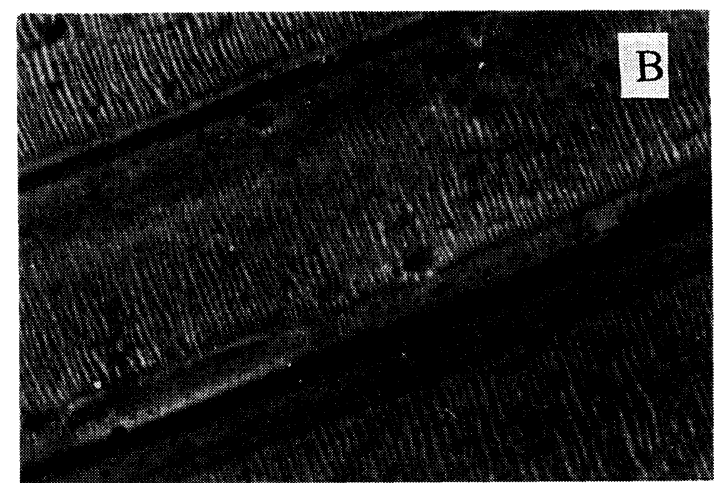

Figure 3. Polarized light micrographs of coply(ester imide) 1d (magnification; 320 fold). A, thread schlieren texture at $250^{\circ} \mathrm{C}$; $\mathrm{B}$, banded texture annealing to room temperature. 


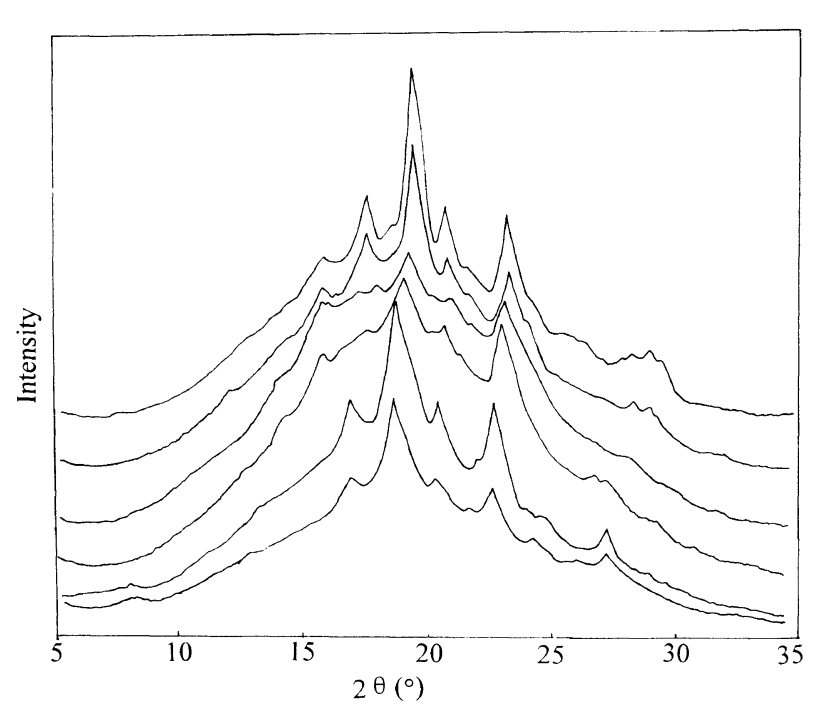

Figure 4. WAXD powder patterns of copoly(ester imide)s 1a, 1b, 1d-1g (from bottom to top) measured at room temperature.

melting point was only $287^{\circ} \mathrm{C}$ which was much lower than that of poly $(p$-oxybenzoate $)\left(T_{\mathrm{m}} \geqslant 450^{\circ} \mathrm{C}\right)$. The fact may be explained as that the polymer primarily consisted of short blocks of POB units along the mainchain instead of a homopolymer of PHB or a copolymer with longer blocks of POB units. Therefore, it was reasonable to consider that there was no possibility of the formation of homopolymer of PHB or copolymer containing long blocks of POB structure in other copoly(ester imide)s (1a-1f) which were completely soluble in organic solvent. The above results suggested that compositional heterogeneity should result from copolymerization when the reactivities of the comonomers were not equal. In other words, the copoly(ester imide)s especially with very high content of PHB were not truly random in monomer sequence whereas other copoly(ester imide)s were nearly random.

The thermal stabilities of these copoly(ester imide)s were evaluated by TGA performed in air at a rate of $10^{\circ} \mathrm{C} \mathrm{min}^{-1}$. The results are listed in Table I. It was found that the thermal stability slightly raised as the increasing of PHB molar ratio gradually. All copoly(ester imide)s began to decompose after about $350^{\circ} \mathrm{C}$ and the total loss mass at $400^{\circ} \mathrm{C}$ was $5-10 \%$.

WAXD powder patterns of all copoly(ester imide)s $\mathbf{1 a}-\mathbf{1 g}$ were measured at room temperature. It was characteristic for the WAXD patterns of these polymers that a series of sharp reflections showed up between $2 \theta=15^{\circ}$ and $25^{\circ}$ (Figure 4). The reflection at $2 \theta=20^{\circ}$ represented a lateral distance of $4.6+0.1 \AA$ between neighboring chains as was typical for many aromatic polyesters. ${ }^{6,15}$ From the reported papers, the homopolyester from PHB existed in three crystal modifications. ${ }^{12,19}$ Of which both of modification I and II had orthorhombic cell with dimensions $a=7.52 \AA, b=5.70 \AA$, $c=12.49 \AA$, and $a=3.77 \AA, b=11.06 \AA, c=12.89 \AA$, respectively. Our study, together with others, revealed a sequence change from modification II to I with the increasing of PHB fraction incorporated. In the case of 1g, most reflections (in particular the most prominent one) agreed with those of modification I of pure PHB. The WAXD results showed that the copoly(ester imide) containing high level content of PHB consisted of a short blocks of PHB along the mainchain which agreed well with the above interpretation from DSC measurements.

\section{Properties of Copoly(ester imide)s Containing different Structure of Diphenols}

DSC measurements were conducted at a heating rate of $20^{\circ} \mathrm{C} \mathrm{min}^{-1}$. In the case of $1 \mathbf{k}-\mathbf{1 n}$, only $T_{\mathrm{g}}$ could be detected. These polymers showed no crystalline melting transitions and presumably were mainly amorphous in nature. Also, these polymers did not exhibit birefringence in their melts which indicated that the structures of these polymers did not favor the paralleled alignment of the chains in their melts. Whereas for $\mathbf{1 h}-\mathbf{1 j}$, one broad and shallow endotherm could be observed. Under the observation of polarized light microscopy, these polymers could form nematic phase above their $T_{\mathrm{m}}$ immediately.

The stereogeometry and the bulkiness of substituents were considered to be the two most important factors in controlling the thermotropic liquid crystalline characteristic of the copoly(ester imide)s investigated here. The electronic or polar effect of the substituents on the liquid crystalline properties was not as clear as the steric effect and seemed to be relatively minor in comparison. The copoly(ester imide)s from linear diphenols (1h-1j) could form a nematic mesophase over a wide temperature range, whereas the nonlinear bisphenol spacers containing large or bulky central substituents between the two phenolic rings (in $\mathbf{1 m}$ and $\mathbf{1 n}$ ) could lead to nonliquid crystalline or isotropic compositions. The difference in the degree of nonlinearity or bending caused by the presence of the middle substituents of the bisphenol monomers were all within about a $5^{\circ}$ angle, which indicated that the degree of molecular bending caused by these substituents was approximately the same. The bond angles around the center atoms of the substituents ranged from about $105^{\circ}$ to $110^{\circ}$. The differences in relative sizes of the substituents, however, were much greater, and it was to be expected that the larger group caused increasing separation of the parallel polymer chains to destabilize the nematic mesophase. ${ }^{20,21}$ In fact, the nonlinear bisphenol spacers containing large or bulky central substituents (e.g., $\mathrm{C}\left(\mathrm{CH}_{3}\right)_{2}$ and $\mathrm{SO}_{2}$ ) between the two phenolic rings were found to be more effective in destroying the liquid crystallinity of resulting copoly(ester imide)s than those with smaller substituents (e.g., $\mathrm{C}=\mathrm{O}$ ). The copoly(ester imide) $\mathbf{1} \mathbf{k}$ was unique in that the resorcinol unit did not have a middle substituent, as in bisphenols, but its presence induced a bend of $120^{\circ}$ along the backbone of the polymer chains, destroying the linearity. Again, the nonliearity was expected to reduce the parallel association of the polymer chains in the nematic state and, thereby, to decrease the stability of mesophase.

\section{CONCLUSION}

A series of copoly(ester imide)s had been synthesized by thermal condensation of a dicarboxylic acid containing two internal imide rings, $p$-hydroxybenzoic acid and diphenols with different structures. For all the resulting copoly(ester imide)s $(\mathbf{1 a - 1 g )}$ containing bis- 
(4-hydroxylphenyl)ketone, a nematic mesophase was formed above their melt. As the molar ratio of PHB increased, the mesophase range became larger. The temperature range of mesophase of poly(ester imide)s containing PHB molar ratio up to $40 \%$ were wide enough for processing from their anisotropic melt. However, the copoly(ester imide) with higher PHB content such as $80 \mathrm{~mol} \%$ consisted of short blocks of PHB unit along its chain. For the copoly(ester imide)s containing different structures of diphenols, only those from linear diphenols (1h-1j) or nonlinear diphenol with small substituent such as $\mathrm{C}=\mathrm{O}$ group between the two phenolic rings (1g) could exhibit thermotropic liquid crystalline behavior, whereas the copoly(ester imide)s from nonlinear diphenols with larger or bulky central substituent such as $\mathrm{C}\left(\mathrm{CH}_{3}\right)_{2}$ and $\mathrm{SO}_{2}$ group were non-liquid crystalline polymers.

\section{REFERENCES}

1. A. Blumstein, Ed., "Liquid Crystallaine Order in Polymer," Academic Press Inc., New York, N.Y., 1978.

2. A. Ciferi, W. R. Krigbaum, and R. B. Meyer, Eds., "Polymer Liquid Crystals," Academic Press Inc., New York, N.Y., 1982.

3. A. A. Picella, L. Nicodemo, and L. Nicolais, Rheol. Acta, 19, 291 (1980).

4. L. Nicodemo, A. A. Picella, and L. Nicolais, Polym. Eng. Sci.,
21, 151 (1981).

5. T. S. Chung, Polym. Eng. Sci., 26, 901 (1986).

6. H. R. Kricheldorf and R. Pakull, Maromolecules, 21, 551 (1988).

7. H. R. Kricheldorf and R. Pakull, Mol. Cryst. Liq. Cryst. Inc. Nonlin. Opt., 57, 13 (1988)

8. H. R. Kricheldorf, R. Pakull, and S. Buchner, Maromolecules, 21, 1929 (1988)

9. H. R. Kricheldorf, Mol. Cryst. Liq. Cryst. Sci. Technol. Sect A, 254, 87 (1994).

10. J. De Abajo, S. G. Babe, and J. Fontan, Angew. Makromol. Chem., 19, 121 (1971).

11. L. N. Stanley (to General Aniline \& Film Corp.), U.S. Pat., 3 073866 (1963).

12. H. R. Kricheldorf, G. Schwarz, and W. Nowatzky, Polymer, 30, 936 (1989).

13. R. W. Lenz and J.-I. Jin, Macromolecules, 14, 1405 (1981).

14. S. E. Beford and A. H. Windle, Polymer, 31, 616 (1990).

15. W. J. Jackson and H. F. Knhfuss, J. Polym. Sci., Polym. Chem. Ed., 14, 2042 (1976).

16. W. J. Jackson and H. F. Knhfuss, J. Polym. Sci, Polym. Chem. Ed., 19, 121 (1981).

17. S. C. Simmens and S. W. S. Hearle, J. Polym. Sci., Polym. Phys. Ed., 18, 871 (1980).

18. C. Viney, A. M. Donald, and A. H. Windle, J. Mater. Sci., 18, 1136 (1983).

19. G. Lieser, J. Polym. Sci., Polym. Phys. Ed., 21, 1611 (1983).

20. J.-I. Jin, S. Antoun, C. Ober, and R. W. Lenz, Br. Polym. J., 112, 132 (1980).

21. F. E. McFarlane, V. A. Nicely, and T. G. Davis, "Contemporary Topics in Polymer Science," Vol. 2, E. M. Pearce and J. R. Schaefgen, Ed., Plenum Press, New York, N.Y., 1977, p 109ff. 